\title{
Lessons learnt from recent citizen science initiatives to document floods in France, Argentina and New Zealand
}

\author{
Jérôme Le Coz ${ }^{1,3, a}$, Antoine Patalano ${ }^{2}$, Daniel Collins ${ }^{3}$, Nicolás Federico Guillén ${ }^{2}$, Carlos Marcelo García ${ }^{2}$, \\ Graeme M. Smart ${ }^{3}$, Jochen Bind ${ }^{3}$, Antoine Chiaverini ${ }^{3,1}$, Raphaël Le Boursicaud ${ }^{1}$, Guillaume Dramais ${ }^{1}$ and Isabelle Braud $^{1}$ \\ ${ }^{1}$ Irstea, Unité de Recherche Hydrologie-Hydraulique, 5 rue de la Doua BP 32108, 69616 Villeurbanne Cedex, France \\ ${ }^{2}$ Institute for Advanced Studies for Engineering and Technology (IDIT CONICET/UNC) and CETA - FCEFyN - Universidad Nacional de \\ Córdoba (CETA) - CONICET, Av. Velez Sarsfield 1611, Ciudad Universitaria, Córdoba, Argentina \\ ${ }^{3}$ NIWA, Applied Hydrology, Hydrodynamics, 10 Kyle Street, Riccarton, Christchurch, New Zealand
}

\begin{abstract}
New communication and digital image technologies have enabled the public to produce and share large quantities of flood observations. Valuable hydraulic data such as water levels, flow rates, inundated areas, etc., can be extracted from photos and movies taken by citizens and help improve the analysis and modelling of flood hazard. We introduce recent citizen science initiatives which have been launched independently by research organisations to document floods in some catchments and urban areas of France, Argentina and New Zealand. Key drivers for success appear to be: a clear and simple procedure, suitable tools for data collecting and processing, an efficient communication plan, the support of local stakeholders, and the public awareness of natural hazards.
\end{abstract}

\section{Introduction}

New communication and digital image technologies have enabled the public to produce and share large quantities of flood observations. Valuable hydraulic data such as water levels, flow rate estimates, inundated areas, etc., can be extracted from photos and movies taken by citizens and help improve the analysis and modelling of flood. As for other research fields, citizen science initiatives on flood hydrology have emerged in the recent years (cf. e.g. [1]).

We introduce three recent citizen science initiatives which have been launched independently by research organisations to document floods in some catchments and urban areas of Argentina, France and New Zealand. While the three projects differ in their objectives, methods and hydrological situations, they provide convergent feedback on the potential and limitations of such initiatives for flood hydrology.

\section{The three projects}

\subsection{The Flood Chasers Project}

The researchers of the National University of Córdoba have developed and implemented the Flood Chasers Project ("Cazadores de crecidas" in Spanish, [2]) to populate a database of videos and digital photos of flash floods in rivers of the province of Córdoba recorded and shared by citizens using advanced digital technology. Flood movies recorded by citizens are then processed to

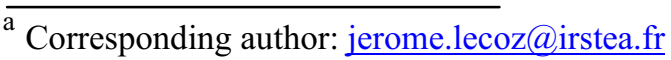

estimate river discharges using image velocimetry techniques such as Large Scale Particle Image Velocimetry (LSPIV, [3]). During the last rainy season (2014-2015), extreme hydrological events occurred and in some cases the data obtained with this technique is the only information available to characterise the observed hydrological events.

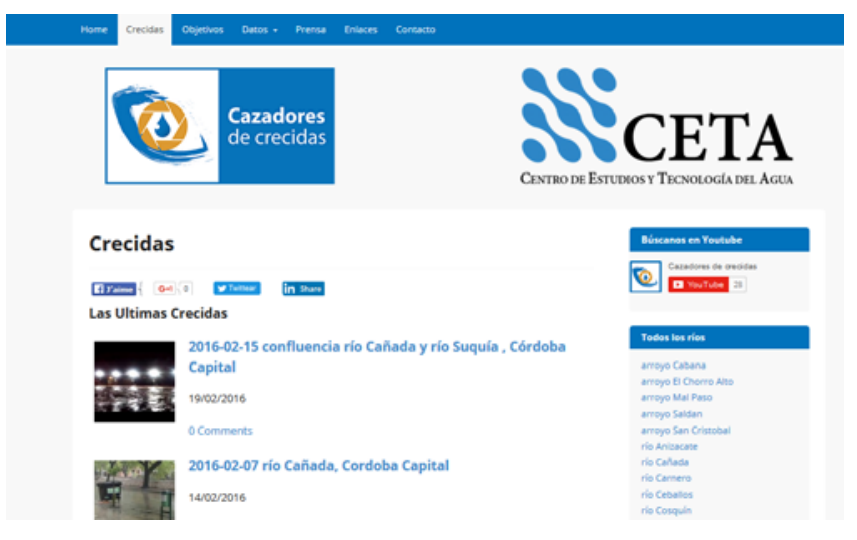

Figure 1. The page of the website of the Flood Chasers Project which lists recent flood movies of interest

The first step was to create a website ${ }^{\mathrm{a}}$ with domain of the University, performing then an intensive dissemination of the existence of this webpage in major newspapers and some television channels. On the project website people can upload their flood videos along with

\footnotetext{
${ }^{\mathrm{a}}$ http://www.cazadoresdecrecidas.unc.edu.ar/
} 
metadata (recording date and time, location of the river section, etc.). The website provides guidelines about the best way to make contributions that are useful for quantifying flood discharges. Users who are interested in participating in the Flood Chasers Project can send or upload their videos using different platforms (i.e. Dropbox, Mega and WeTransfer) through basic tutorials generated by the scientists. A webpage also lists all the recorded floods and include the flow results if the video has been suitable for analysis (Figure 1). In turn, there is a YouTube channel called "Cazadores de Crecidas" in which the project leaders upload their own collection of videos, also published on the website.

Image sequences of recorded videos are processed using Matlab tool PIVlab [4] for calculating the velocity field from each pair of images. Each of these instantaneous velocity fields is processed and the average displacement field in pixels per image pair is calculated. The results are exported to the RIVeR (Rectification of Image Velocity Results) toolbox, another Matlab toolbox [5] where the displacement data are transformed into velocity data in $\mathrm{m} / \mathrm{s}$ after rectification of perspective effects due to the oblique capture of the videos with respect to the flow surface.

The methodology was notably applied to a video recorded by the witness of a flood that occurred in the Los Chorrillos Creek, in the city of Carlos Paz, Córdoba, Argentina, after an extraordinary flood event occurred on the morning of 14 March 2014. The recurrence period of the rainfall event generating this flood was estimated to be 56 years with a duration of 160 minutes. The witness uploaded this video to a website of a newspaper in the province of Córdoba (cf. Figure 2).

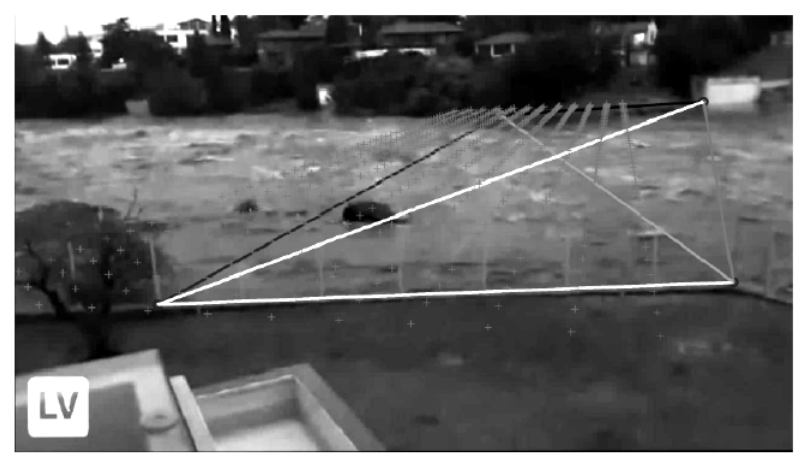

Figure 2. Image of the flood in the Los Chorrillos Creek in the city of Carlos Paz, Córdoba, Argentina on 14 March 2014 and grid points for correcting the computed velocities.

The scientists recognised the house from which the video was captured and proceeded to contact the author. Subsequently, the scientists went to the place and surveyed the cross-section bathymetry using an Acoustic Doppler Current Profiler (ADCP) mounted on a mobile platform (cf. Figure 3). The camera movement due to the videographer holding the camera by hand without a tripod was preliminarily corrected. Such movement creates significant errors in the processing of the images. Then, the surface velocity profile was computed (cf. Figure 3) and integrated throughout the transect using a depth-average to surface flow velocity ratio of 0.85 , the default value generally used for uniform flow of average roughness $[6,7]$. The estimated flow rate was $984 \mathrm{~m}^{3} / \mathrm{s}$.
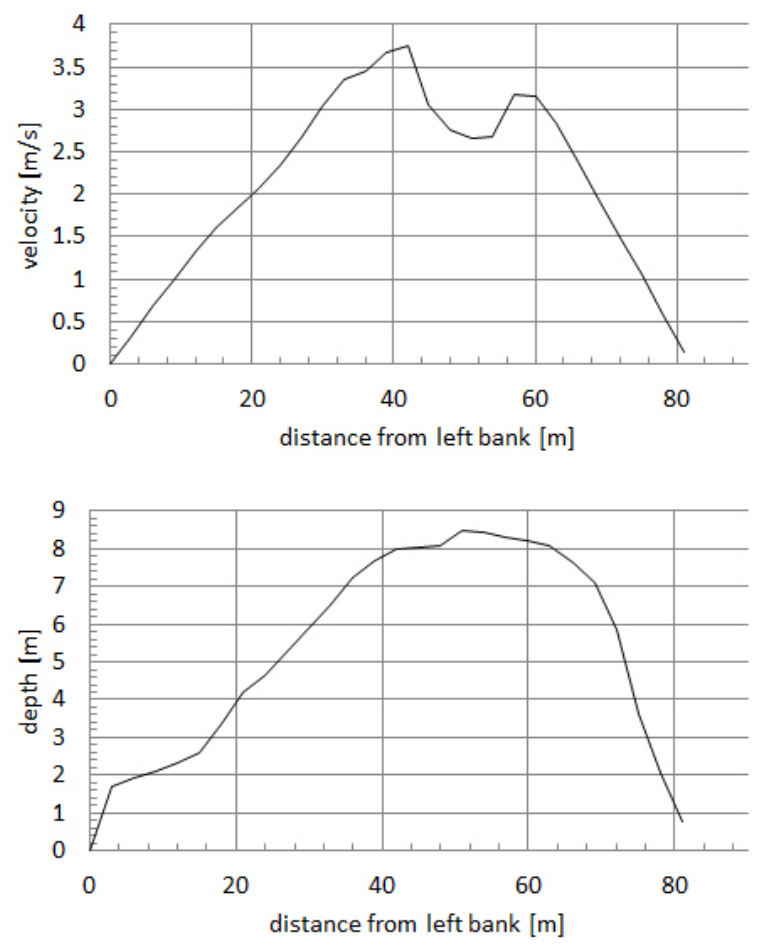

Figure 3. Bathymetry of the cross-section of interest and cross-profile of surface velocities obtained by LSPIV

The relationship of the Flood Chasers Project leaders with government authorities is more than optimal. The minister of water, environment and energy of the Córdoba province is actually a professor at Universidad Nacional de Córdoba (at leave) who is interested in the implementation of the technique. The results obtained in the project have been used by the government to hydrologically evaluate some of the recorded events. Due to this interest the project has received support from the government including logistics for conducting the required surveys (topography survey, field work, etc.). For the next rainy season, the researchers are looking for training groups of people who can be great partners, for example the civil defence workers and advanced students (16 to 17 years old) from high schools that are located near rivers. A strong message of safety is also transmitted. It is very important to avoid any life in danger and be sure there is no risk in recording a video.

\subsection{The FloodScale Project}

As part of the $\mathrm{ANR}^{\mathrm{b}}$ FloodScale project (France) on Mediterranean flash floods [8], a similar action was independently launched throughout the Ardèche river catchment, South-East France. The FloodScale project, a contribution to the $\mathrm{HyMeX}^{\mathrm{c}}$ project (Hydrological cycle in the Mediterranean Experiment) was designed to make

\footnotetext{
${ }^{\mathrm{b}}$ Agence Nationale pour la Recherche (National Research Agency, France)

c www.hymex.org
} 
progress in the understanding and modelling of flash floods. Specific communication actions focussed on the determination of flood discharges throughout the Ardèche river catchment (France) using home movies shared by observers and volunteers. Safety instructions and a simplified field procedure (cf. poster in Figure 4) were shared through local media and were made available in French and English on the project website ${ }^{\mathrm{d}}$.

The processing of flood movies to extract surface flow velocities and discharges is based on the LSPIV technique originally proposed by Fujita et al. [9] and also used in the Flood Chasers project. The applicability of the LSPIV technique to flood home movies was investigated by Le Boursicaud et al. [10]. Using flood movies recorded by non-professional witnesses usually raises specific issues and requires some image pre-processing before the LSPIV analysis. LSPIV analysis was conducted using Fudaa-LSPIV [11], a free, user-friendly software available online ${ }^{\mathrm{e}}$. Image pre-processing was conducted using Hugin, another free software available online. The complete procedure to collect and pre-process home movies for further LSPIV analysis comes as a short methodological guide [12].

Simple procedures for taking useful flood movies, highlighting safety warning (cf. Figure 4) have been disseminated to the public through various media including the project website ${ }^{\mathrm{f}}$ and local media (newspapers, radio). Legal aspects including a copyright transfer form have been settled with the help of Irstea's legal services. Communication campaign was well received by locals and municipalities, but jeopardised by local issues (concurrent update of official flood risk mapping) and lack of coordination with and support from local authorities due to safety concerns. After long discussions, the communication campaign had to be postponed.

Partly due to communication restrictions, few videos were received by the scientists, even after the series of significant floods which occurred during the 2014 autumn. And none of those was actually usable because they generally did not follow the recommendations. However, some useful movies were harvested by scientists after each flood of interest, especially drone videos (cf. Figure 5) shared on YouTube ${ }^{\mathrm{g}}$ by a local company $^{\text {h }}$ specialising in UAV-borne image recording. As often, the water stage estimation appears to be the main source of uncertainty (cf. Table 1). However, discharge estimates were found to be consistent with the rated flows at the upstream gauging station.

\footnotetext{
d https://floodscale.irstea.fr/donnees-en/videosamateurs-de-rivieres-en-crue/videos-amateurs-derivieres-en-crue

e https://forge.irstea.fr/projects/fudaa-lspiv/files

$\mathrm{f}$ https://floodscale.irstea.fr

$\mathrm{g}$ https://www.youtube.com/watch?v=4lgws8pvFyg

$\mathrm{h}$ http://www.ardechevideo.com/
}

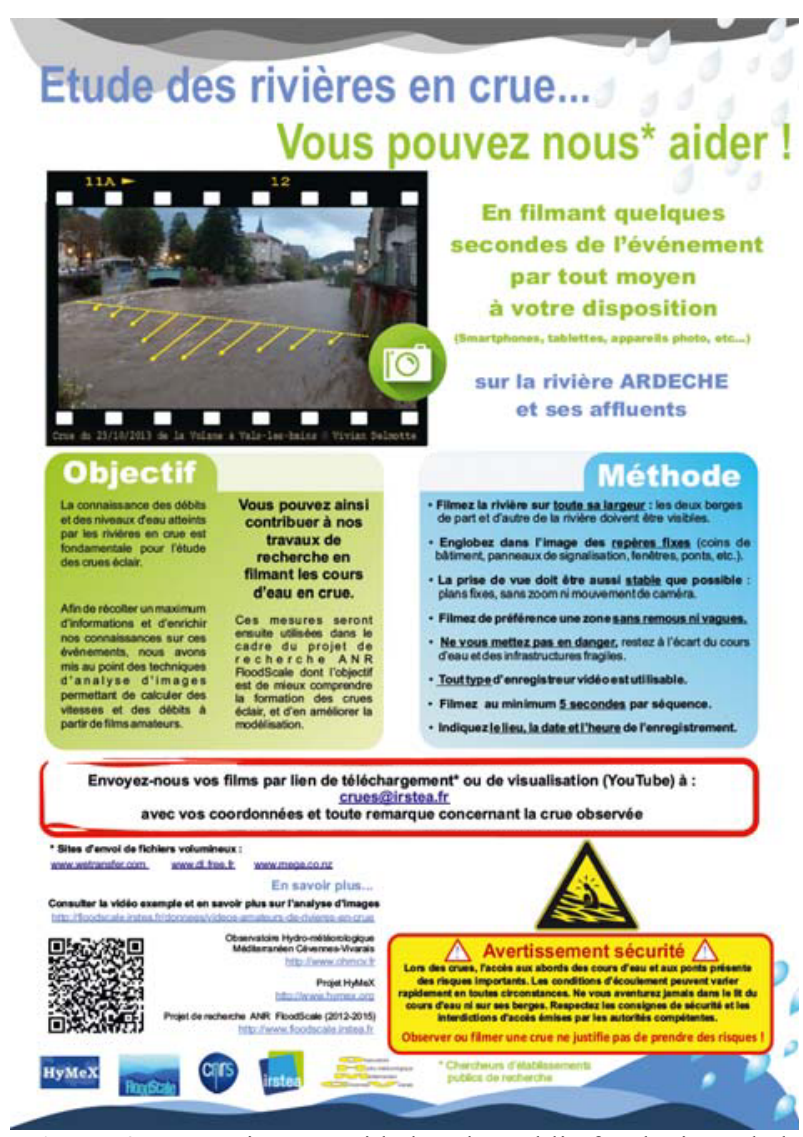

Figure 4. Instructions provided to the public for the intended poster campaign of the FloodScale Project

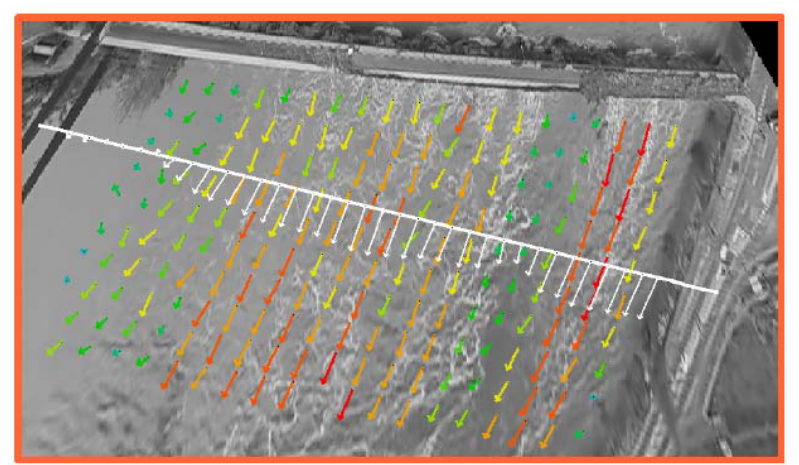

Figure 5. Applying LSPIV to a drone video of the Ardèche River at Sampzon Bridge, France, shared on YouTube after 2014 floods.

\begin{tabular}{|c|c|c|c|}
\hline $\begin{array}{c}\text { Water } \\
\text { Level } \\
(\mathrm{m})\end{array}$ & $\begin{array}{c}\text { LSPIV } \\
\text { Discharge Q } \\
\left(\mathrm{m}^{3} / \mathrm{s}\right)\end{array}$ & $\begin{array}{c}\text { Q difference } \\
(\%) \\
\text { Time lag: } \\
30 \mathrm{~min}\end{array}$ & $\begin{array}{c}\text { Q difference } \\
(\%) \\
\text { Time lag: } \\
60 \mathrm{~min}\end{array}$ \\
\hline 94.5 & 1053 & +16 & +25 \\
\hline 94.0 & 913 & +3.6 & +13 \\
\hline 93.5 & 795 & -11 & +0.6 \\
\hline
\end{tabular}

Table 1. Discharge results and comparison with records from upstream gauging station 


\subsection{The RiskScape Project}

The New Zealand national institute NIWA has called citizens to contribute to floodmapping during the May 2014 inundation events in the city of Christchurch, as part of the RiskScape ${ }^{i}$ project. Two days after the flood peak, members of the public were invited, via press releases to mainstream media, a scientific $b \log ^{j}$ and outreach via social media (Facebook, Twitter), to send photos of maximum flood levels to NIWA, indicating when and where each photo was taken. When applicable, water surface levels were derived from the photos in conjunction with LiDAR scans of the city. The resulting point data were interpolated, along with additional survey

i www.riskscape.org.nz

j http://sciblogs.co.nz/waiology/2014/03/07/calling-forchristchurch-flood-photos/ data, to derive a flood hazard model to calculate flood risk and potential losses across the city.

Over 600 photos were received (Figure 6). Ultimately, 300 photos were used to get a fix on 289 water levels around the city. Combined with field surveys, the resulting inundation map (Figure 7) indicates flooding along the Avon and Heathcote Rivers as well as various residential suburbs throughout Christchurch, including the severely impacted Flockton Basin. High media and public interest suggested that, in addition to providing useful data, the public engagement fostered a greater appreciation of flood hydrology and its scientific study. The resultant information has been invaluable in understanding the changed flood risk for post-earthquake Christchurch, was used to validate hydrodynamic models and is being used to plan mitigation, response and evacuation plans and to calculate human and economic costs of flooding.
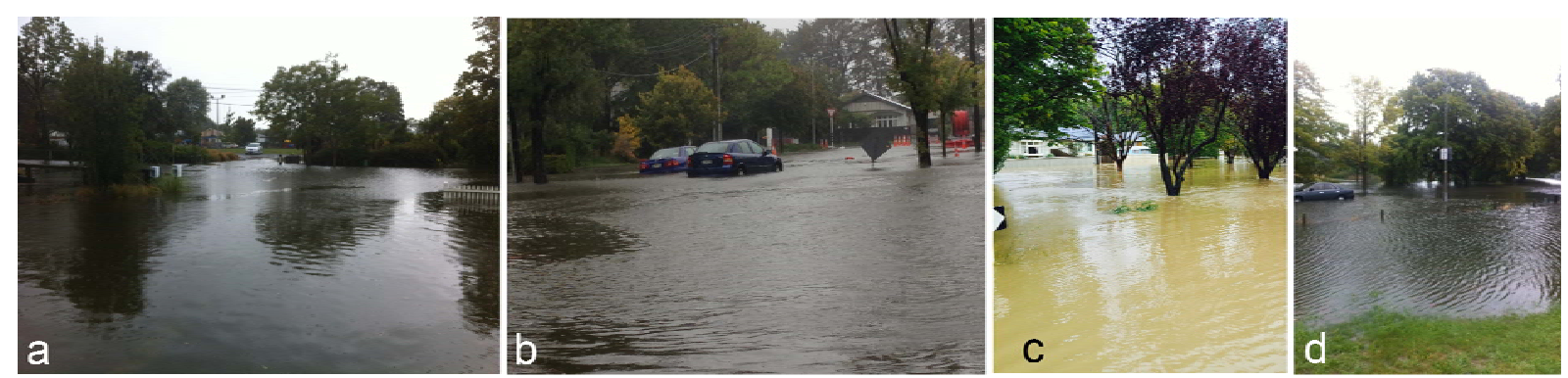

Figure 6. Photos of the May 2014 inundation in Christchurch received from the public: (a) Slater St, Richmond; (b) Francis Ave, Mairehau; (c) Buxton Tce flow gauging site, St Martins; (d) Intersection of Oxford Tce and Barbadoes St.

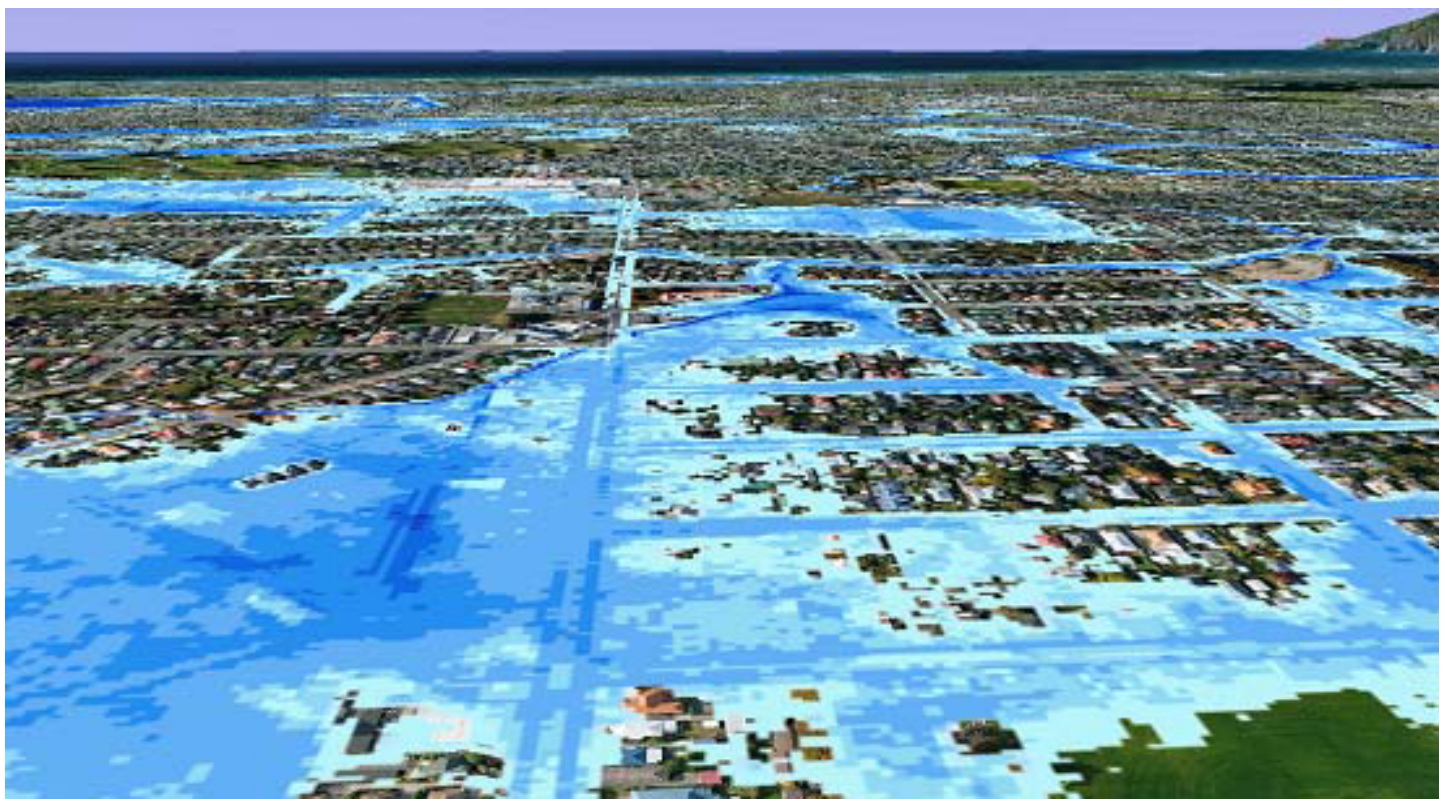

Figure 7. Inundation extent and depth across Christchurch, $5^{\text {th }}$ May 2014, based on photos received from the public. The Flockton basin is in the foreground. Where houses are shown there is no modelled surface flooding on the property; where there are no houses shown surface flooding is indicated by the shade of blue (darker $=$ deeper). 


\section{Lessons learnt}

\subsection{A clear and simple procedure}

The three projects have produced procedures in the form of simple instructions for recording the images and sending the data in good agreement with their distinct objectives. The type of images and metadata, the protocols to send them to the scientists and the safety and copyright aspects were dealt with in a concise and precise manner. However, for the capture of valuable movies, a written procedure may not be sufficient and additional training should be provided as tutorials and short movies, e.g. on collaborative websites like WikHydro in France ${ }^{k}$.

\subsection{Suitable data collecting and processing}

It is necessary to develop platforms able to collect large quantities of data coming with contrasted formats and quality levels. Website forms and uploads, as well as smart (apps) or basic (textos) phones, are efficient tools to collect crowdsourced data, as long as the effort required from the user is kept minimal. However, it sometimes remains more efficient for scientists to harvest adequate image materials from sharing platforms and social networks.

The processing of the collected data generally requires specific techniques and tools that are not previously available off the shelf. It is important to carefully review the quality of the crowdsourced data, in particular through post-event field investigation and cross-checking of the results with other sources of information. The use of crowdsourced hydrologic data in models and scientific studies also requires suitable techniques that are able to assimilate data coming with contrasted and possibly large uncertainties.

\subsection{An efficient communication plan}

Communication is key to efficiently mobilise flood observers, make them aware of flood-related dangers (and discourage them from risking their lives), avoid conflicts with local authorities, and provide feedback on the use of collected data. Simple and direct explanations are essential, even when it comes to science or legal terms. Such initiatives are usually well received by locals and the media. Communication efforts should be directed at both the general public and specific community groups.

The reported experience highlights the necessity to adapt the communication vectors to each project. Communicating through radio and TV allows reaching a wide audience. Local newspapers and scientific blogs can probably reach a more specific audience but can be efficient to release punctual and periodic reminders of the projects. Distributing flyers and displaying posters at key

\footnotetext{
${ }^{\mathrm{k}}$ http://wikhydro.developpement-durable.gouv.fr/
}

observation points and at places attended by the public may dramatically increase the quantity of image materials at particularly strategic sites. Social networks like Twitter and Facebook are essential as they allow to reach a wide audience and to do it at any time. Being constantly active in the whole range of available media is key.

\subsection{Support from local stakeholders}

As consistently illustrated in the polarised French and Argentinian experiences, getting the support of local authorities or not can significantly enhance or jeopardise your citizen science project. In the specific context of the FloodScale project, calling for images before rather than during or just after the flood appeared to be the main source of concerns for the administration. However, the support of local stakeholders and authorities should still be sought actively. There is always a chance that they realise the potential of citizen science initiatives for the success and acceptance of flood risk policies.

\subsection{Public engagement}

The call is much more successful when the public and the media are prepared and aware of natural hazards, as was the case in Christchurch, New Zealand, after the earthquakes of 2010 and 2011. Social studies could also profit from such crowdsourced feedback from people on how they have been affected by the flood and how they have reacted, as done through calls and interviews in social science projects as done in HyMex ${ }^{1}$. Provided there is sufficient expert oversight during project design and data analysis, such citizen science seems a viable means of improving our understanding of flood risk. However, in some cases the value of the obtained data is much less than the impact and engagement of the citizen community [1]. Feedback to the public is absolutely essential, through any available means: project website, online database, publication of results, follow-ups on scientific blogs $^{\mathrm{mn}}$ and communication through the media.

\section{Conclusions}

The reported three projects are typical of emerging citizen science initiatives for crowdsourcing flood hydrology data. They illustrate their great potential for improving flood risk assessment in interaction with the local communities. Beyond the technical and communication challenges, this is an efficient way to enhance the culture of flood risk and make people more engaged collectively. We hope that our feedback may help such initiatives emerge and develop successful strategies.

\footnotetext{
${ }^{1}$ www.hymex.org and web form: http://goo.gl/forms/q80gfQbPNN

${ }^{\mathrm{m}} \mathrm{http}: / /$ sciblogs.co.nz/waiology/2014/06/16/citizenscientists-help-map-christchurch-flooding/

${ }^{n}$ http://sciblogs.co.nz/waiology/2014/09/04/full-citizenscience-flood-map-for-christchurch-march-2014/
} 


\section{Acknowledgements}

The Flood Chasers project acknowledges the support of the Government of the Córdoba Province, Argentina, through the PROTRI project. The FloodScale project was funded by the French National Research Agency (ANR) under Contract No ANR 2011 BS56 027, which contributes to the HyMeX program. Catherine Ambroise-Rendu and Thierry Fournier (Irstea) contributed to the FloodScale communication campaign. Collaboration between NIWA and Irstea was enhanced by the PHC Dumont D'Urville project 34185SH (20152016) and the Irstea grant and NIWA support for the scientific visit of J. Le Coz at NIWA. All the citizens who have provided images for the three projects are gratefully thanked.

\section{References}

1. Lowry C. S. and Fienen, M. N. (2013). CrowdHydrology: Crowdsourcing Hydrologic Data and Engaging Citizen Scientists. Ground Water, 51, 151-156

2. Patalano A., Moreno L., Marcelo García C. and Guillén N. F. (2015) Desarrollo e implementación del proyecto "Cazadores de crecidas" en ríos de la provincia de Córdoba [Development and implementation of the Cazadores de crecidas project in rivers of the Córdoba province, in Spanish], IV Simposio sobre métodos experimentales en hidráulica, La Plata, Argentina, 2 p.

3. Patalano A., Marcelo García C., Guillén N., García C., Díaz E., Rodriguez A. and Ravelo A. (2014) Evaluación experimental de la técnica de velocimetría por seguimiento de partículas a gran escala para la determinación de caudales en ríos serranos [Experimental evaluation of large scale particle tracking velocimetry technique for flow discharge measurements in mountains rivers, in Spanish], Aqua-LAC, 6(1), 17-24

4. Patalano, A., and García, C. M. (2016) RIVeR Towards affordable, practical and user-friendly toolbox for Large Scale PIV and PTV techniques. IAHR RiverFlow Conference, St. Louis, USA.

5. Thielicke W. and Stamhuis E. J. (2014) PIVlab Towards Userfriendly, Affordable and Accurate Digital Particle Image Velocimetry in MATLAB, Journal of Open Research Software, 2.

6. Le Coz J., Hauet A., Pierrefeu G., Dramais G. and Camenen B. (2010) Performance of image-based velocimetry (LSPIV) applied to flash-flood discharge measurements in Mediterranean rivers, Journal of Hydrology, 394 (1-2), 42-52

7. Welber M., Le Coz J., Laronne, J.B., Zolezzi G., Zamler D., Dramais G., Hauet A. and Salvaro M. (2016) Field assessment of non-contact stream gauging using portable surface velocity radars (SVR), Water Resources Research (in press).

8. Braud I., Ayral P.-A., Bouvier C., Branger F., Delrieu G., Le Coz J., Nord G., Vandervaere J.-P., Anquetin S., Adamovic M., Andrieu J., Batiot C.,
Boudevillain B., Brunet P., Carreau J., Confoland A., Didon-Lescot J.-F., Domergue J.-M., Douvinet J., Dramais G., Freydier R., Gérard S., Huza J., Leblois E., Le Bourgeois O., Le Boursicaud R., Marchand P., Martin P., Nottale L., Patris N., Renard B., Seidel J.L., Taupin J.-D., Vannier O., Vincendon B., Wijbrans A. (2014) Multi-scale hydrometeorological observation and modelling for flash flood understanding, Hydrology and Earth System Sciences, 18(9), 3733-3761

9. Fujita I., Muste M., Kruger A. (1998) Large-scale particle image velocimetry for flow analysis in hydraulic engineering applications. Journal of Hydraulic Research, 36(3), 397-414

10. Le Boursicaud R., Pénard L., Hauet A., Thollet T., and Le Coz J. (2016) Gauging extreme floods on YouTube: Application of LSPIV to home movies for the post-event determination of stream discharges, Hydrological Processes, 30, 90-105

11. Le Coz J., Jodeau, M., Hauet, A., Marchand, B. and Le Boursicaud, R. (2014) Image-based velocity and discharge measurements in field and laboratory river engineering studies using the free Fudaa-LSPIV software. In RIVER FLOW 2014, 1961-1967

12. Le Boursicaud R., Le Coz J., and Dramais G. (2015) Guide méthodologique - Collecte et préparation de film amateur en vue d'une exploitation par analyse d'image [Methodological Guide - Collection and preprocessing of home movies for operations by image analysis, in French], Technical report, Irstea, 23 p. 